\title{
THE INFLÙENCE OF INITIAL TEMPERATURE ON FLAME ACCELERATION AND DEFLAGRATION-TO-DETONATION TRANSITION
}

\author{
G. Ciccarelli, J. L. Boccio, and T. Ginsberg \\ Brookhaven National Laboratory \\ Department of Advanced Technology \\ Building 130 \\ P.O. Box 5000 \\ Upton, NY 11973-5000 \\ and \\ H. Tagawa \\ Japanese Nuclear Power Engineering Corporation
}

\begin{abstract}
The influence of initial mixture temperature on deflagration-to-detonation transition (DDT) has been investigated experimentally. The experiments were carried out in a $27-\mathrm{cm}$-inner diameter, 21.3-meter-long heated detonation tube, which was equipped with periodic orifice plates to promote flame acceleration. Hydrogen-air-steam mixtures were tested at a range of temperatures up to $650 \mathrm{~K}$ and at an initial pressure of $0.1 \mathrm{MPa}$. In most cases, the limiting hydrogen mole fraction which resulted in transition to detonation corresponded to the mixture whose detonation cell size, $\lambda$, was approximately equal to the inner diameter of the orifice plate, $d$ (e.g., $d / \lambda \approx 1)$. The only exception was in dry hydrogen-air mixtures at $650 \mathrm{~K}$ where the DDT limit was observed to be 11 percent hydrogen, corresponding to a value of $d / \lambda$ equal to 5.5. For a 10.5 percent hydrogen mixture at $650 \mathrm{~K}$, the flame accelerated to a maximum velocity of about $120 \mathrm{~m} / \mathrm{s}$ and then decelerated to below $2 \mathrm{~m} / \mathrm{s}$. This observation indicates that the $d / \lambda=1$ DDT limit criterion provides a necessary condition but not a sufficient one for the onset of DDT in obstacle-laden ducts. In this particular case, the mixture initial condition (i.e., temperature) resulted in the inability of the mixture to sustain flame acceleration to the point where DDT could occur. It was also observed that the distance required for the flame to accelerate to the onset of detonation was a function of both the hydrogen mole fraction and the mixture initial temperature. For example, decreasing the hydrogen mole fraction or increasing the initial mixture temperature resulted in longer transition distances.
\end{abstract}

\section{DISCLAIMER}

This report was prepared as an account of work sponsored by an agency of the United States Government. Neither the United States Government nor any agency thereof, nor any of their employees, makes any warranty, express or implied, or assumes any legal liability or responsibility for the accuracy, completeness, or usefulness of any information, apparatus, product, or process disclosed, or represents that its use would not infringe privately owned rights. Reference herein to any specific commercial product, process, or service by trade name, trademark, manufacturer, or otherwise does not necessarily constitute or imply its endorsement, recommendation, or favoring by the United States Government or any agency thereof. The views and opinions of authors expressed herein do not necessarily state or reflect those of the United States Government or any agency thereof. 
DISCLAIMER

Portions of this document may be illegible in electronic image products. Images are produced from the best available original document. 


\section{INTRODUCTION}

Under postulated severe accident scenarios in water-cooled nuclear power plants and in certain industrial chemical processes, combustible mixtures can be present at elevated temperature. The threat of detonation initiation under such conditions has sparked interest in the effects of initial mixture temperature on flame acceleration and transition to detonation phenomenon. The experimental results presented here address this issue by investigating flame acceleration and transition to detonation in a heated obstacle-filled detonation tube.

Since the pioneering work of Laffite [1], it has been well known that for certain mixtures a flame propagating in a long tube could accelerate to the point where a detonation is initiated in the gas. In order for transition to detonation to occur, the flame must accelerate to a velocity in excess of the speed of sound in the unburnt mixture. As the flame accelerates to such high velocities, compression waves are generated ahead of the flame which eventually coalesce into a leading shock wave. If this shock wave attains sufficient strength, a detonation can form in the compressed gas between the flame and the shock wave. Stroboscopic laser-schlieren movies taken of the final stages of flame acceleration leading to transition to detonation clearly show a strong leading shock wave followed by a train of compression waves originating at the accelerating turbulent flame [2]. The photographs indicate that the location of the transition to detonation, or the so-called "explosion within the explosion," always occurs within the shock-flame complex, typically in the boundary layer.

Shchelkin [3] first showed that the transition distance from flame to cietonation (i.e., run-up distance) could be dramatically shortened by roughening the duct walls with turbulencegenerating obstacles. Obstacles generate gradients in the flow field ahead of the flame resulting in large-scale "flame folding" [4]. Superimposed on the large-scale flame fold are small-scale shear layers produced at the obstacle edges. The increase in flame surface area due to flame folding and the increase in turbulence intensity in the mean flow resuits in an enhanced burning rate. The coupling between the burning rate and the induced flow ahead of the flame results in a feedback mechanism which promotes flame acceleration. An accelerating turbulent flame in an obstacle-laden duct generates compression waves ahead of it much like in the smooth duct. The local high temperature and pressure generated by the reflection of the leading shock wave from an obstacle face promotes transition to detonation.

The exact mechanism by which a detonation is formed has yet to be conclusively identified. The Shock Wave Amplification by Coherent Energy Release (SWACER) mechanism has been proposed by Lee [5] to describe the process by which spatial nonuniformities in the chemical induction time in a mixture can result in the formation of a detonation. In the case of DDT resulting from flame acceleration, the nonuniformities can be due to local fluctuations in the compressed gas between the flame and the leading shock wave. The induction time gradient required for the SWACER mechanism can result from temperature gradients generated from local turbulent mixing of combustion products and fresh mixture.

A large body of experimental data exists in the literature dealing with flame acceleration and transition to detonation phenomenon. A comprehensive study of flame acceleration leading to the onset of detonation in obstacle-laden tubes was undertaken at McGill University. A series of tests was performed in long tubes with inner diameters of 5,15 , and $30 \mathrm{~cm}[6,7]$. 
In these tests, an array of orifice plates was placed inside the tubes to promote turbulence and thus flame acceleration. Typically, flame acceleration takes place in the first few meters of the tube and is followed by steady-state flame propagation to the end of the tube. The combustion front propagation during this final steady-state phase was classified into two regimes: the "choking" and "quasi-detonation" regimes [6]. In the choking regime, the flame accelerates to a final steady-state velocity that is close to the isobaric sound speed in the products, assuming a constant pressure combustion process. It is argued that the maximum steady-state flame velocity achievable is the speed of sound in the products due to choking of the flow as a result of heat addition from combustion. It has recently been proposed, based on theoretical considerations, that flame propagation in the choking regime could be described as a plane precursor shock wave driven by a Chapman-Jouget (CJ) deflagration [8]. In the quasi-detonation regime, flame acceleration leads to transition to detonation. Due to severe momentum and heat losses from the reaction zone, the detonation wave propagates at a velocity substantially below the theoretical $\mathrm{CJ}$ velocity. It was established that for those mixtures whose average detonation cell size, $\lambda$, was smaller than the orifice plate inner diameter, $d$, resulted in transition to detonation (i.e., $d / \lambda \geq 1$ ). This observation yields a DDT limit criterion, $d / \lambda=1$, which defines the minimum hydrogen concentration required for transition to detonation to occur [7]. When applying the DDT limit criterion, one must keep in mind the uncertainty, in terms of cell nonuniformity, in the experimentally measured cell size. In hydrogen-air-steam mixtures, this uncertainty could be as high as \pm 25 percent of the average cell size $[9,10]$.

Recent experiments have been carried out to investigate the effect of initial mixture temperature on flame acceleration in an obstacle-laden tube [11]. The experiments were carried out in a 6-m-long tube with only half of the tube filled with obstacles. Experiments performed at $573 \mathrm{~K}$ with 32 percent orifice blockage resulted in very limited flame acceleration with no transition to detonation observed. Whereas at $300 \mathrm{~K}$, transition to detonation was readily observed with the same orifice plates. The length of the obstacle field in these experiments was likely insufficient to fully investigate the DDT phenomenon at elevated temperatures.

The objective of the present set of experiments is to characterize the effect of mixture initial temperature on flame acceleration and, most importantly, on the potential for transition to detonation. Using available cell size data for hydrogen-air-steam mixtures at elevated temperatures [10], we will determine if the $\lambda / d=1$ DDT limit criterion applies at elevated initial temperatures up to $650 \mathrm{~K}$. Unlike in the previous experiments reported in [11], the entire length of the test vessel will be filled with orifice plates in order to maximize the distance available for the flame to achieve a steady-state velocity.

\section{EXPERIMENTAL DETAILS}

The experiments were carried out in the Brookhaven National Laboratory High-Temperature Combustion Facility (HTCF) which consists of a 27-cm-inner diameter, 21.3-m-long heated detonation vessel. The vessel is made up of seven equal-length flanged sections. A detailed description of the HTCF detonation vessel, the gas handling system, and other auxiliary equipment can be found in [10]. Flame acceleration is promoted by an array of obstacles placed inside the entire length of the detonation vessel. The obstacles consist of orifice plates 
which are $1.9-\mathrm{cm}$ thick, 27-cm-outer and 20.6- $\mathrm{cm}$-inner diameter, with a 1-tube diameter (i.e., $27 \mathrm{~cm}$ ) spacing. This spacing is maintained by fastening the orifice plates to six axially running threaded rods with nuts on either side of each plate. The threaded rods are anchored to the vessel at each vessel flange location.

The vessel is heated using ceramic bead heating pads which are strapped directly to the outside of the vessel using pipe clamps and are covered with roughly $5 \mathrm{~cm}$ of insulation. The vessel is evacuated using a large Stokes vacuum pump. The test gas is blended dynamically in a mixing chamber where the individual gas constituent flow rates are set using choked venturis. The test gas is introduced into the vessel and quickly ignited using a standard diesel engine glow plug centrally mounted on one of the vessel end plates. Three gas samples are taken just before ignition to verify the gas composition and uniformity in the vessel.

The detonation vessel is equipped with instrumentation ports located every $61 \mathrm{~cm}$ down the length of the tube. The combustion front velocity is derived from time-of-arrival measurements made using photodiode detectors. The photodiode spacing is large, typically $3.05 \mathrm{~m}$, in order to filter the flame velocity measurements of local fluctuations caused by gasdynamic effects associated with the restricted flow through the orifice plates. For slow propagating flames, the intensity of light emitted from the flame is insufficient to obtain a signal from the photodiodes, in which case the flame velocity is determined based on fast response thermocouple signals. Combustion front pressure is measured using PCB113 piezoelectric pressure transducers that are flush mounted on the tube wall. The signals from the photodiodes and pressure transducers are recorded on two digital oscilloscopes, and the thermocouple signals are recorded on a PC-based data acquisition system equipped with thermocouple conditioning software.

\section{EXPERIMENTAL RESULTS}

\section{Flame Propagation at Room Temperature}

Plotted in Fig. 1 is the flame front velocity versus axial distance for three different hydrogen-air mixtures at $300 \mathrm{~K}$. These three experiments characterize the spectrum of flame propagation modes observed in the current study. The various flame propagation regimes have been classified as: (1) detonation, (2) choking, and (3) slow deflagrations.

In Fig. 1, the flame trajectory in the 16 percent hydrogen mixture is typical of steady-state flame propagation in the detonation regime. The flame acceleration takes place in the first six meters followed by a relatively steady propagation at a velocity of $1130 \mathrm{~m} / \mathrm{s}$ with a standard deviation of $22 \mathrm{~m} / \mathrm{s}$. This average velocity is roughly 27 percent below the theoretical $\mathrm{CJ}$ velocity for this mixture. There is a slight overshoot in the velocity before reaching steady state, which is typical of a DDT event. This velocity overshoot is observed, to various degrees, in all the experiments in the detonation regime. Due to the large spacing between photodiodes, the actual velocity overshoot is most likely larger. The flame trajectory shown in Fig. 1 for the 12 percent hydrogen mixture is typical of flame propagation in the choking regime. As in the 16 percent hydrogen case, the flame propagates at a relatively steady velocity after an initial acceleration phase in the first six meters of travel. Although not very evident in this test, there is a velocity overshoot that typically follows the initial flame 
acceleration phase. The average velocity for the flame after six meters is $644 \mathrm{~m} / \mathrm{s}$ with a standard deviation of $8 \mathrm{~m} / \mathrm{s}$. This matches very closely the speed of sound in the products for this mixture. Flame propagation in the 10 percent hydrogen mixture is typical of flame propagation in the slow deflagration regime. The flame velocity measurements for this test were derived from four thermocouples located in the first half of the tube. For the 10 percent hydrogen mixture, the flame initially accelerates to a maximum velocity of about $250 \mathrm{~m} / \mathrm{s}$ and then continuously decelerates to roughly $100 \mathrm{~m} / \mathrm{s}$ by mid vessel. In the present study, there was no evidence of "flame quenching" [6], where the flame is extinguished during the flame acceleration.

Shown in Fig. 2 is a plot of the average flame velocity as a function of the mixture hydrogen mole fraction. For each test in the choking and detonation regime, the average velocity, shown as open circles, is based on measurements obtained in the last half of the vessel. Also shown is the standard deviation in the measurements used to obtain the average velocity. The theoretical curves for the mixture $\mathrm{CJ}$ detonation velocity and the isobaric sound speed in the combustion products are shown as solid lines. The open squares represent the maximum velocity measured for mixtures in the slow deflagration regime.

No abrupt change in the average propagation velocity as a function of hydrogen concentration is noted in Fig. 2 that would indicate a transition between the choking and the detonation regimes. The figure shows a continuous decrease in the average velocity from very close to the $\mathrm{CJ}$ detonation velocity for a 30 percent hydrogen mixture down to just below the isobaric product sound speed for a 13 percent hydrogen mixture. Recall that in the detonation regime, the detonation wave propagates at a sub-CJ detonation velocity due to momentum and heat losses from the reaction zone to the tube and orifice plates. The amount of energy lost is governed by the length of the reaction zone, or detonation cell size, which increases with decreasing hydrogen concentration. The pressure measured near the end of the vessel was used to establish the lower DDT limit to be 15 percent hydrogen. For mixtures of 15 percent hydrogen and higher, the overpressure is scattered about the $\mathrm{CJ}$ detonation pressure, and for mixtures below 15 percent hydrogen, the peak overpressures are below the constant volume combustion pressure [10]. The cell size for a 15 percent hydrogen mixture at $300 \mathrm{~K}$ and $0.1 \mathrm{MPa}$ is about $21.8 \mathrm{~cm} \mathrm{[10],} \mathrm{and} \mathrm{the} \mathrm{inner} \mathrm{diameter} \mathrm{of} \mathrm{the} \mathrm{rings} \mathrm{is} 20.6 \mathrm{~cm}$. Therefore, the ratio $d / \lambda$ equals 1.0 , which is in excellent agreement with the DDT limit criterion proposed by Peraldi et al. [7].

\section{Flame Propagation at Elevated Temperature and With Steam Dilution}

The average flame velocity for hydrogen-air mixtures at $500 \mathrm{~K}$ is plotted versus hydrogen mole fraction in Fig. 3. Here, there is a clear demarcation of the transition from the choking to the detonation regime at 12 percent hydrogen. The experimental average detonation velocity data lies closer to the theoretical $\mathrm{CJ}$ detonation velocity compared to that observed at $300 \mathrm{~K}$, in Fig. 2. For example, for a 15 percent hydrogen mixture, the measured velocity is 15 percent below the $\mathrm{CJ}$ detonation velocity, and at 30 percent hydrogen, the velocity deficit is only 2 percent. This can be attributable to the decrease in cell size (i.e., reaction zone length) with increased initial temperature [10] resulting in less momentum and heat losses. For mixtures between 8 and 11 percent hydrogen, the data follows very closely the theoretical isobaric sound speed of the product gases. The cell size for a 12 percent hydrogen mixture at $500 \mathrm{~K}$ 
and $0.1 \mathrm{MPa}$ is about $13.5 \mathrm{~cm}$ [10] which yields a value of 1.5 for the ratio $d / \lambda$. Considering the uncertainty in the measured detonation cell size, e.g., up to \pm 25 percent as previously indicated, and the resolution of the hydyogen mole fraction between experimental points in Fig. 3 , this value can be considered to be in relative agreement with the $d / \lambda=1$ criterion for DDT transition.

Figure 4 shows the flame trajectory for several hydrogen-air mixtures at $650 \mathrm{~K}$ and $0.1 \mathrm{MPa}$. At this temperature, DDT occurred in 11, 12, and 17.5 percent hydrogen mixtures. It is clear from this figure that the detonation run-up distance increases with decreasing hydrogen concentration. For the 17.5 percent hydrogen mixture, DDT occurs after about six meters of propagation, and from that distance to the end of the vessel, there is a slight decay in the detonation velocity. A similar type of behavior is observed in the 12 percent hydrogen mixture, and for the 11 percent hydrogen mixture, DDT occurs at the end of the vessel. Decreasing the hydrogen mole fraction from 11 to 10.5 percent, results in a benign burn. In the 10.5 percent hydrogen mixture, the flame accelerates to a maximum velocity of about $100 \mathrm{~m} / \mathrm{s}$ and then decays to roughly the laminar burning velocity.

It is difficult to assign an average velocity to any of the velocity profiles shown in Fig. 4 since the detonation never achieves steady-state conditions within the length of the vessel. This is especially true for the leaner mixtures where the run-up distances can be quite large. Therefore, in Fig. 5, the last velocity measurement taken at the end of the vessel (between 16.7 and 19.8 meters) in each experiment carried out at $650 \mathrm{~K}$ is shown as a function of the hydrogen mole fraction. Note these are not average velocities and thus there is no standard deviation shown. The measured detonation velocity decreases smoothly with decreasing hydrogen mole fraction just below the theoretical $\mathrm{CJ}$ detonation velocity. The minimum hydrogen concentration resulting in a DDT is 11 percent hydrogen. As indicated above, for the 10.5 percent hydrogen mixture, the maximum flame velocity is only about $100 \mathrm{~m} / \mathrm{s}$. As a result, no flame propagation in the choking regime was observed. The 11 and 10.5 percent hydrogen tests were repeated several times to verify the observed behavior. The high detonation velocities corresponding to 11 percent hydrogen are the result of DDT occurring at the end of the vessel where the last velocity measurement is taken. The cell size for an

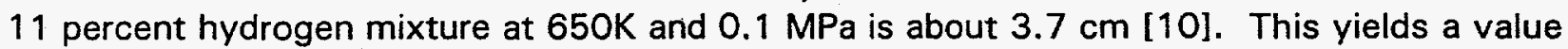
of 5.5 for the ratio $d / \lambda$, which means that at the DDT limit, about five detonation cells pass through the inner diameter of the orifice plate. Even if the uncertainty in the cell size measurement is taken to be a conservative \pm 50 percent, the low end of the $d / \lambda$ ratio at the limit becomes 3.7. Clearly, the observed minimum hydrogen composition of 11 percent for DDT at $650 K$ does not agree with the DDT limit criterion of $d / \lambda=1$, which has been shown to be applicable for the data obtained at $300 \mathrm{~K}$ and $500 \mathrm{~K}$.

As mentioned above, due to the long detonation run-up distances at $650 \mathrm{~K}$, the detonation does not achieve steady-state conditions within the length of the vessel. In order to reduce the run-up distance, a series of experiments was performed where the first two of the seven flanged sections (e.g., 6.1 meters) were each maintained at 400K while the remaining sections were heated to the test temperature of $650 \mathrm{~K}$. In these experiments, transition occurred within the range of 7.6 and 10.1 meters from the point of ignition, which is just outside the cold section, leaving sufficient distance to the end of the vessel for the detonation to achieve steady conditions. With the first 6.1 meters of the vessel at $400 K$, DDT occurred in hydrogen- 
air mixtures down to 9.5 percent hydrogen. Therefore, mixtures of 9.5 and 10 percent hydrogen, which did not transition to a detonation when the vessel was completely heated, are now observed to result in transition to detonation. The cell size for a 9.5 percent hydrogen in air mixture at $650 \mathrm{~K}$ is $4.6 \mathrm{~cm}$ [10]. This yields a value of $4.5 \mathrm{for} \mathrm{d} / \lambda$, which is still well above the DDT criterion found to be valid for the tests at $300 \mathrm{~K}$ and $500 \mathrm{~K}$.

The influence of steam dilution on flame acceleration and DDT phenomenon was studied in hydrogen-air mixtures at initial temperatures of $400 \mathrm{~K}, 500 \mathrm{~K}$, and $650 \mathrm{~K}$. In these tests, the steam dilution fraction was held constant, and the ratio of the hydrogen to air was varied (i.e., hydrogen mole fraction on a dry basis). In this way, one can obtain a minimum hydrogen composition resulting in DDT for a given steam dilution and initial temperature. The results from these tests are summarized in the following table which lists the minimum hydrogen concentration which resulted in transition to detonation and the corresponding $d / \lambda$ ratio.

Table 1: Flame Acceleration Limits for Hydrogen-Air-Steam Mixtures Without Venting

\begin{tabular}{|c|c|c|c|c|}
\hline \multirow{2}{*}{$\begin{array}{c}\text { Temp } \\
(\mathrm{K})\end{array}$} & $\begin{array}{c}\text { Steam Dilution } \\
(\%)\end{array}$ & Choking Limit & \multicolumn{2}{|c|}{ DDT Limits } \\
\cline { 3 - 5 } & & $\%$ Hydrogen & $\%$ Hydrogen & $\mathrm{d} / \lambda$ \\
\hline \hline 400 & 10 & 12 & 18 & 0.7 \\
\hline 500 & 25 & 14 & 24 & 1.5 \\
\hline 650 & 25 & 16 & 19 & 0.8 \\
\hline
\end{tabular}

The results for all three initial temperatures are in relatively good agreement with $d / \lambda=1$ criterion.

\section{DISCUSSION}

The present experiments have shown that, in general, the DDT limit was found to lie in the range $0.7 \leq d / \lambda \leq 1.5$ for different initial temperatures, with and without steam. This finding is consistent with the $d / \lambda=1$ DDT limit criterion proposed by Peraldi et al. [7]. The exception was in tests performed in dry hydrogen-air mixtures at an initial temperature of 650K. In these tests, DDT was observed in mixtures containing 11 percent hydrogen or more, which corresponds to a value of $d / \lambda>5.5$. Although this result does not violate the $d / \lambda>1$ criterion for the possibility of DDT, it is at variance with the DDT limit of $d / \lambda=1$ which was found to apply at all the other initial conditions.

In most cases, a plot of the average flame velocity versus hydrogen mole fraction indicates that the DDT limit represents the transition between the choking and the detonation regimes. For example, for a mixture slightly leaner in hydrogen than the hydrogen mixture at the DDT limit, the flame was observed to accelerate to a constant velocity equal to the speed of sound in the products (i.e., choking regime). Flame propagation in the choking regime is characterized by the precompression of the mixture by the leading shock wave before combustion. The DDT limit is governed by the existence of a mixture state le.g., temperature, vorticity, etc.) behind the precursor shock wave which is favorable for detonation initiation. 
There is a fundamental difference in the observed DDT limit in dry hydrogen-air mixtures at $650 \mathrm{~K}$ and that observed at all the other conditions. This difference being, that in the dry hydrogen-air experiments at $650 \mathrm{~K}$, no flame propagation was observed in the choking regime. For the 10.5 percent hydrogen-air mixture, which is 0.5 percent leaner in hydrogen than the hydrogen-air mixture at the DDT limit, the flame velocity peaked at only $100 \mathrm{~m} / \mathrm{s}$. Therefore, the failure to observe transition for this composition can be attributed to the inability of the mixture to sustain flame acceleration.

It was also observed that DDT could be promoted by artificially increasing the flame acceleration rate. For example, in a 10 percent hydrogen mixture at $650 \mathrm{~K}$, flame acceleration was severely limited, and no DDT was observed. DDT was observed in the same 10 percent hydrogen mixtures by promoting flame acceleration by the use of the initial cold section. Note, DDT occurred near the end of the tube, far removed from the colder sections in the first 6.1 meters of the tube. Therefore, the initial cold section acted only as a booster for the flame and played no direct role in the local DDT phenomenon. In the experiments reported in [11], a similar boosting of the flame acceleration was achieved by using higher blockage orifice plates in the first half of the obstacle section. This resulted in transition for mixtures which otherwise would not have resulted in DDT when the smaller blockage orifice plates were used throughout.

For hydrogen-air mixtures with 25 percent steam dilution at $650 \mathrm{~K}$, the DDT limit was found to be 19 percent hydrogen, which yields a value of $d / \lambda=1.2$. This is in close agreement with the $d / \lambda=1$ DDT limit criterion and corresponds to the transition from the choking regime to the detonation regime. Unlike the dry hydrogen-air mixtures at an initial temperature of $650 \mathrm{~K}$, the steam diluted mixtures leaner than the DDT limit were capable of accelerating to a velocity equal to the sound speed in the burnt products. Two of the important parameters which govern the rate of flame acceleration are the density ratio of the unburnt to the burnt gas and the mixture laminar burning velocity. Mixtures with a larger density ratio and laminar burning velocity result in higher flame acceleration rates. The density ratio across the flame and the laminar burning velocity for a 19 percent hydrogen in air mixture with 25 percent steam is 2.4 and $2.7 \mathrm{~m} / \mathrm{s}$, respectively. The density ratio and burning velocity in the dry 11 percent hydrogen in air mixture is 2.2 and $1.9 \mathrm{~m} / \mathrm{s}$, respectively. This indicates that the potential for flame acceleration in the steam diluted DDT limit mixture (e.g., $d / \lambda=1.2$ ) is higher than the dry 11 percent mixture which has a smaller cell size and thus a larger value of $d / \lambda(e . g ., 5.5)$.

\section{CONCLUSION}

Flame propagation in the heated obstacle-laden tube used in the present experiments consists of an initial flame acceleration phase followed by a steady-state phase. The various flame propagation regimes observed are similar to those described in [6]. In general, the DDT limit data could be correlated with the $d / \lambda=1$ criterion proposed by Peraldi et al. [7]. The only exception was in the dry hydrogen-air mixtures at $650 \mathrm{~K}$, where the DDT limit was observed to be 11 percent hydrogen which corresponds to a value of $d / \lambda=5.5$. This DDT limit dropped to 9.5 percent hydrogen $(\mathrm{d} / \lambda=4.2)$ when the first 6.1 meters of the vessel was maintained at $400 \mathrm{~K}$ with the rest of the vessel at $650 \mathrm{~K}$. This indicates that the $d / \lambda=1$ DDT limit criteria provides a necessary but not sufficient condition for the onset of DDT in obstacle-laden ducts. 
In this particular case, the mixture initial condition (i.e., temperature) resulted in the inability of the mixture to sustain flame acceleration to the onset of DDT.

The detonation run-up distance, which in this geometry is governed primarily by the rate of flame acceleration, was found to be a function of the hydrogen mole fraction and the initial temperature. The detonation run-up distance was found to decrease with increasing hydrogen mole fraction, up to stoichiometric conditions, and with decreasing initial temperature.

\section{ACKNOWLEDGEMENTS}

This research is sponsored by the U.S. Nuclear Regulatory Commission and the Ministry of International Trade and Industry of Japan through the Nuclear Power Engineering Corporation of Japan.

The authors would like to thank the NRC Technical Monitor, Dr. Asimios Malliakos, for his support and guidance through the course of this project and his helpful suggestions in the review of the work.

The authors would also like to thank C. Finfrock and L. Gerlach for aiding in the running of the experiments. 


\section{REFERENCES}

1. Laffite, P., Compt. Rendu, 186, p. 951, 1928.

2. Urtiew, P., and Oppenheim, A., Proc. of Royal Society London Series A, 295, pp. 13-28., 1966.

3. Shchelkin, K., Zh. Exp. Teor. Fiz. (USSR), 10, pp. 823-827, 1940.

4. Moen, I. O., Donato, M., Knystautas, R., and Lee, J. H., Combustion and Flame 39: 21-32 (1980).

5. Lee, J. H., Knystautas, R., and Yoshikawa, N., Acta Astronautica, 5, p. 971, 1978.

6. Lee, J. H., Knystautas, R., and Chan, C., Twentieth Symposium (International) on Combustion, The Combustion Institute, Pittsburgh, 1984, pp. 1663-1672.

7. Peraldi, O., Knystautas, R., and Lee, J. H., Twenty-First Symposium (International) on Combustion, The Combustion Institute, Pittsburgh, 1986, pp. 1629-1637.

8. Chu, R.,Clark, J., and Lee, J. H., Proceedings of the Royal Society London A, 441, pp. 607-623, 1993.

9. Tieszen, S. R., et al., Progress in Astronautics and Aeronautics 106: 205 (1986).

10. Ciccarelli, G., et al., USNRC Report NUREG/CR-6391, BNL-NUREG-52482, 1996.

11. Beauvais, B., Mayinger, F., and Strube, G., ASME/JSME Nuclear Engineering Conference-Volume 1, pp. 425-433, 1993. 


\section{LIST OF FIGURES}

1 Combustion front velocity versus propagation distance in three hydrogen-air mixtures at $300 \mathrm{~K}$ and $0.1 \mathrm{MPa}$.

2 Combustion front velocity versus hydrogen mole fraction for hydrogen-air mixtures at $300 \mathrm{~K}$ and $0.1 \mathrm{MPa}$. Open circles denote the average velocity over roughly the second half of the vessel and bars represent the standard deviation in the measured velocities. Open squares denote the maximum flame velocity for slow deflagrations.

3 Combustion front velocity versus hydrogen mole fraction for hydrogen-air mixtures at $500 \mathrm{~K}$ and $0.1 \mathrm{MPa}$. Open circles denote the average velocity over roughly the second half of the vessel and bars represent the standard deviation in the measured velocities. Open squares denote the maximum flame velocity for slow deflagrations.

4 Combustion front velocity versus propagation distance for hydrogen-air mixtures at $650 \mathrm{~K}$ and $0.1 \mathrm{MPa}$.

5 Combustion front velocity versus hydrogen mole fraction for hydrogen-air mixtures at $650 \mathrm{~K}$ and $0.1 \mathrm{MPa}$. Open circles denote the flame velocity at the end of the vessel. Open squares denote the maximum flame velocity for slow deflagrations. 


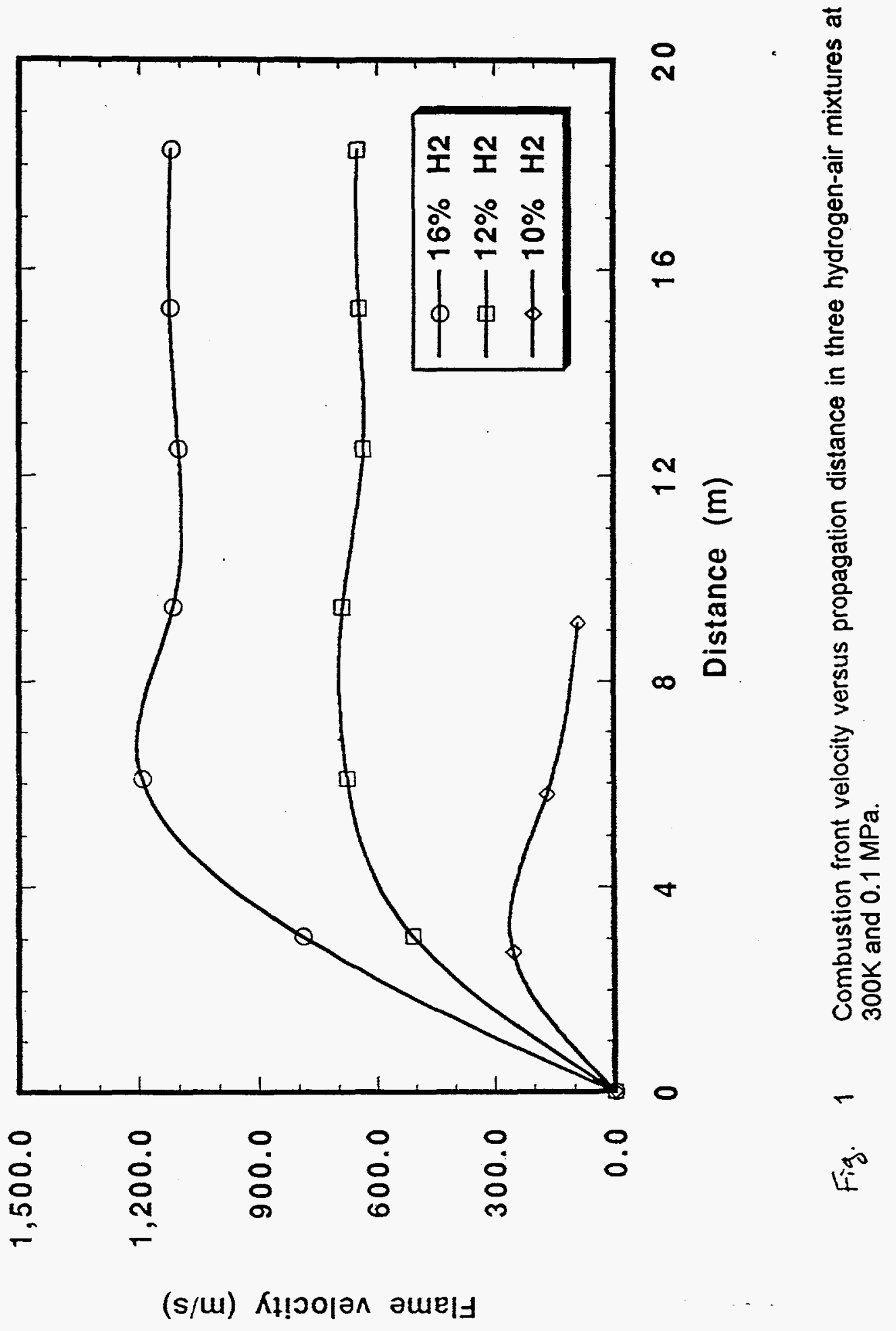




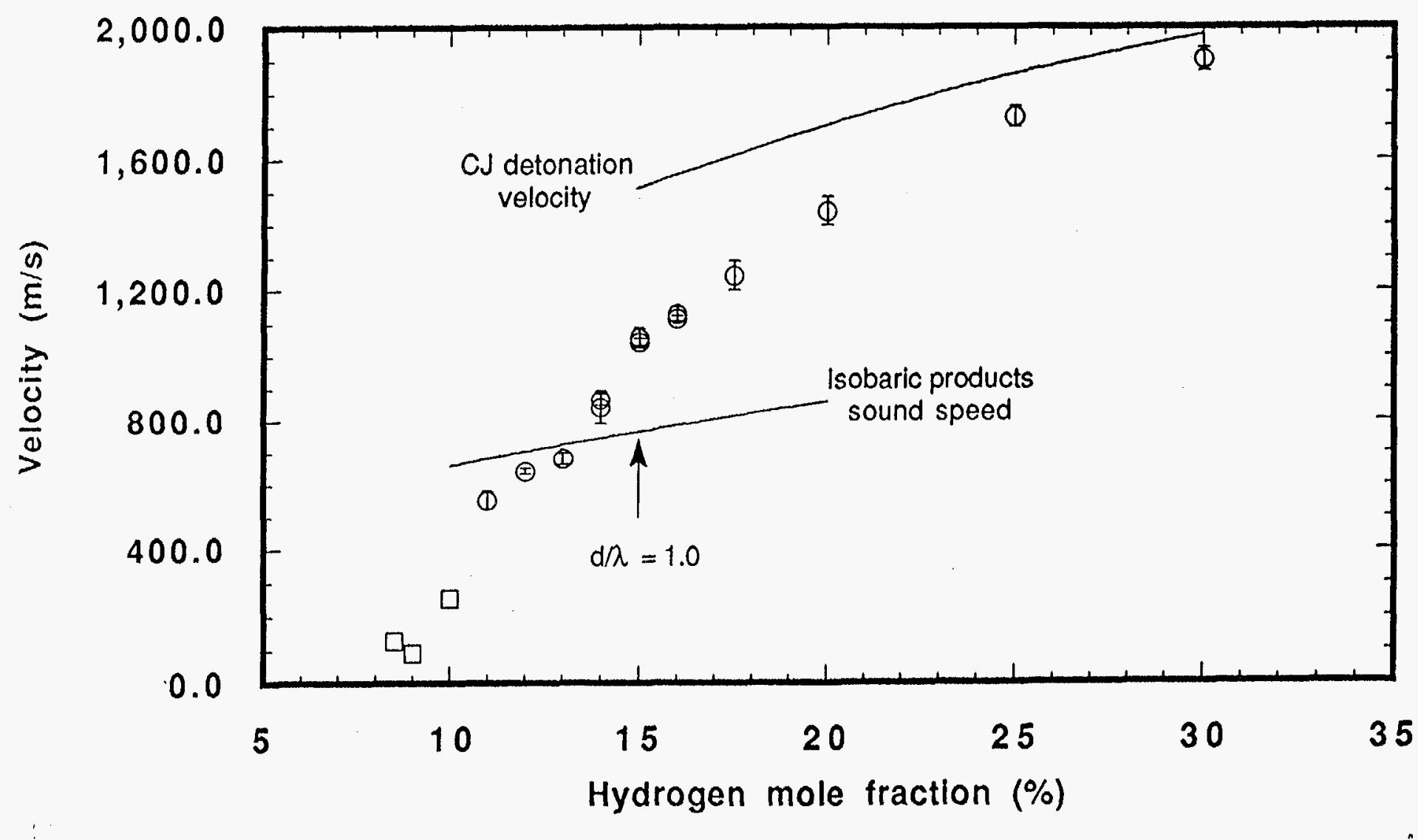

Fig. 2 Combustion front velocity versus hydrogen mole fraction for hydrogen-air mixtures at $300 \mathrm{~K}$ and $0.1 \mathrm{MPa}$. Open circles denote the average velocity over roughly the second half of the vessel and bars represent the standard deviation in the measured velocities. Open squares denote the maximum flame velocity for slow deflagrations. 


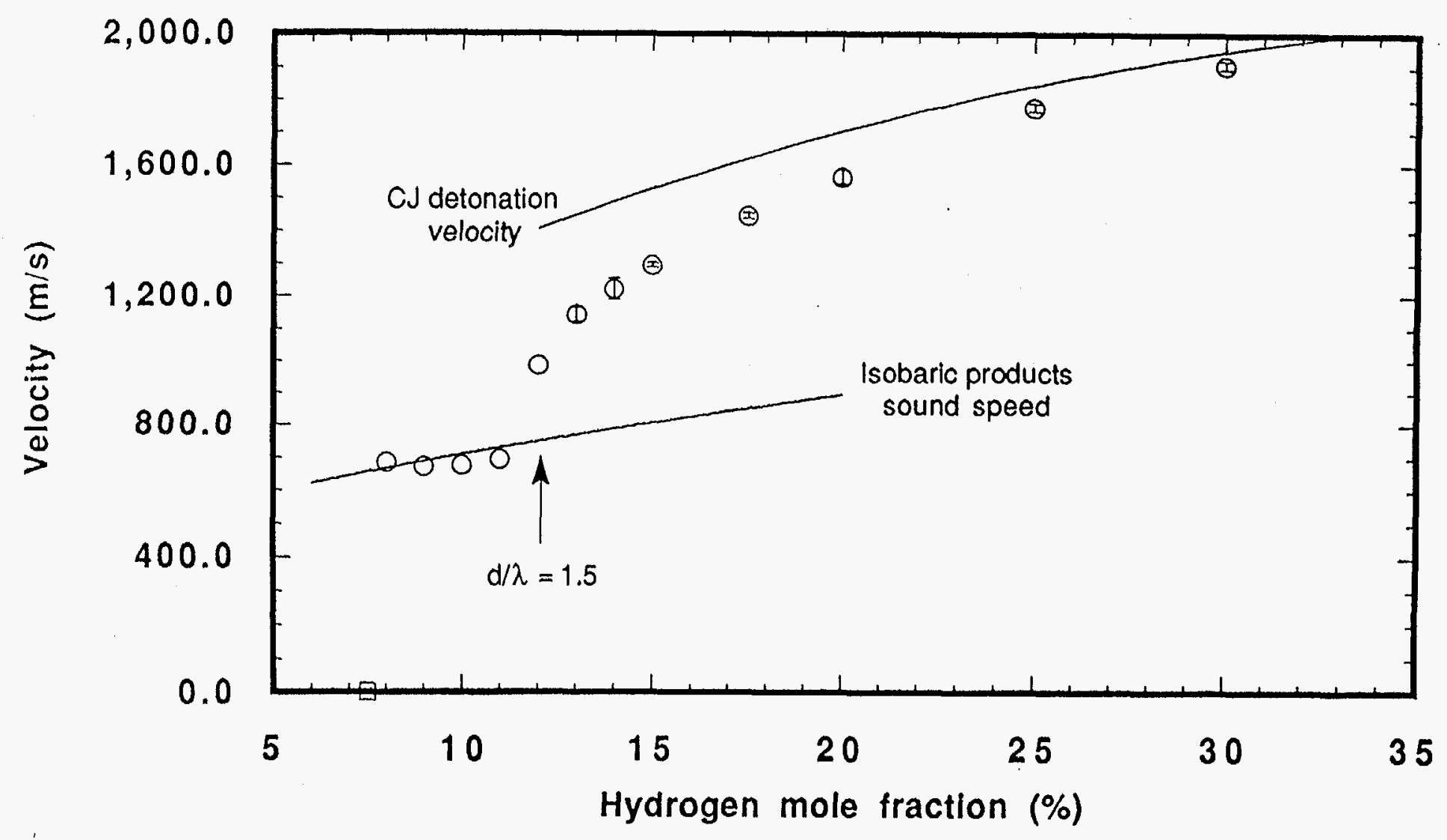

Fig. 3 Combustion front velocity versus hydrogen mole fraction for hydrogen-air mixtures at 500K and $0.1 \mathrm{MPa}$. Open circles denote the average velocity over roughly the second half of the vessel and bars represent the standard deviation in the measured velocities. Open squares denote the maximum flame velocity for slow deflagrations. 


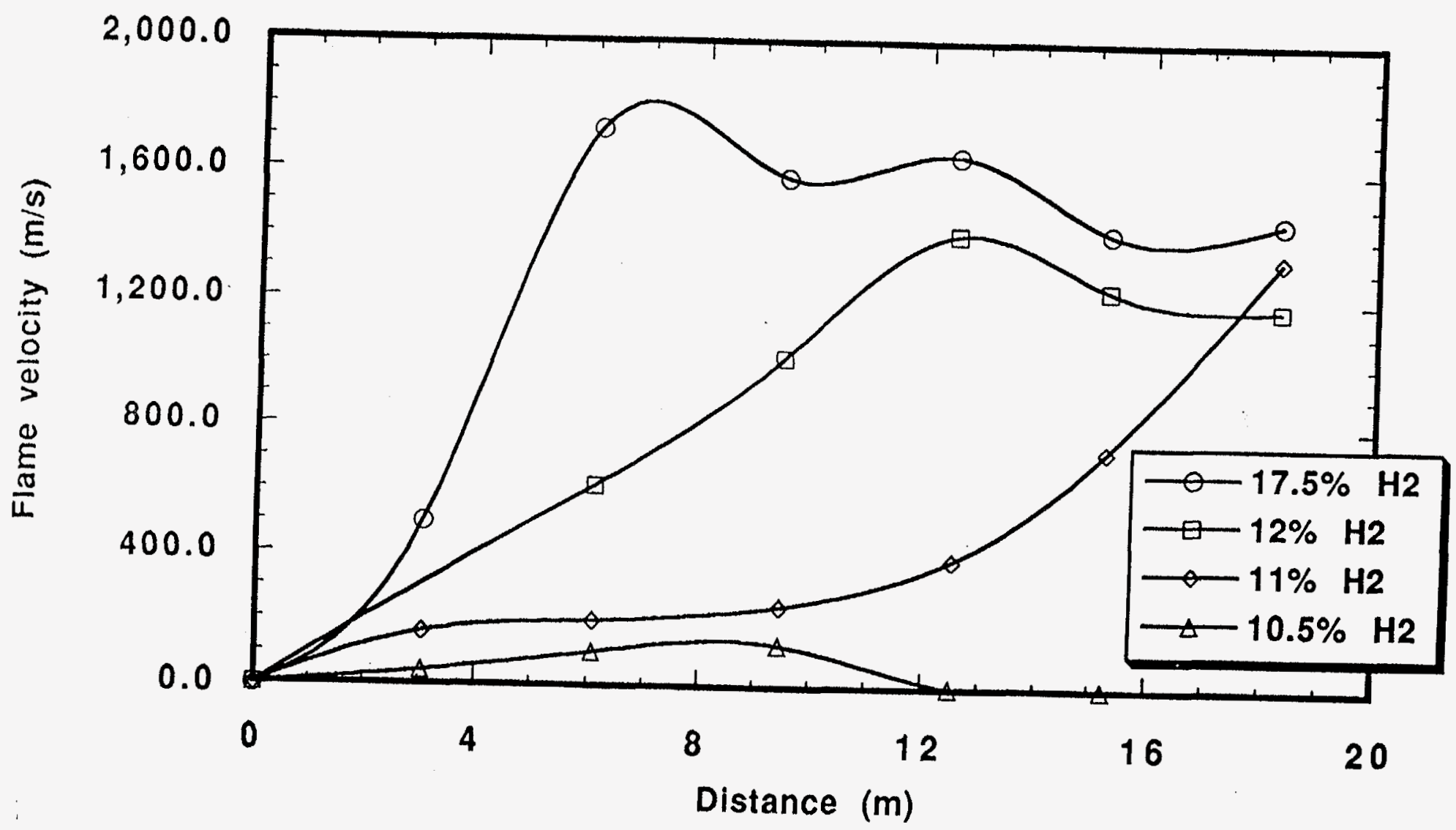

Fig. 4 Combustion front velocity versus propagation distance for hydrogen-air mixtures at $650 \mathrm{~K}$ and $0.1 \mathrm{MPa}$. 


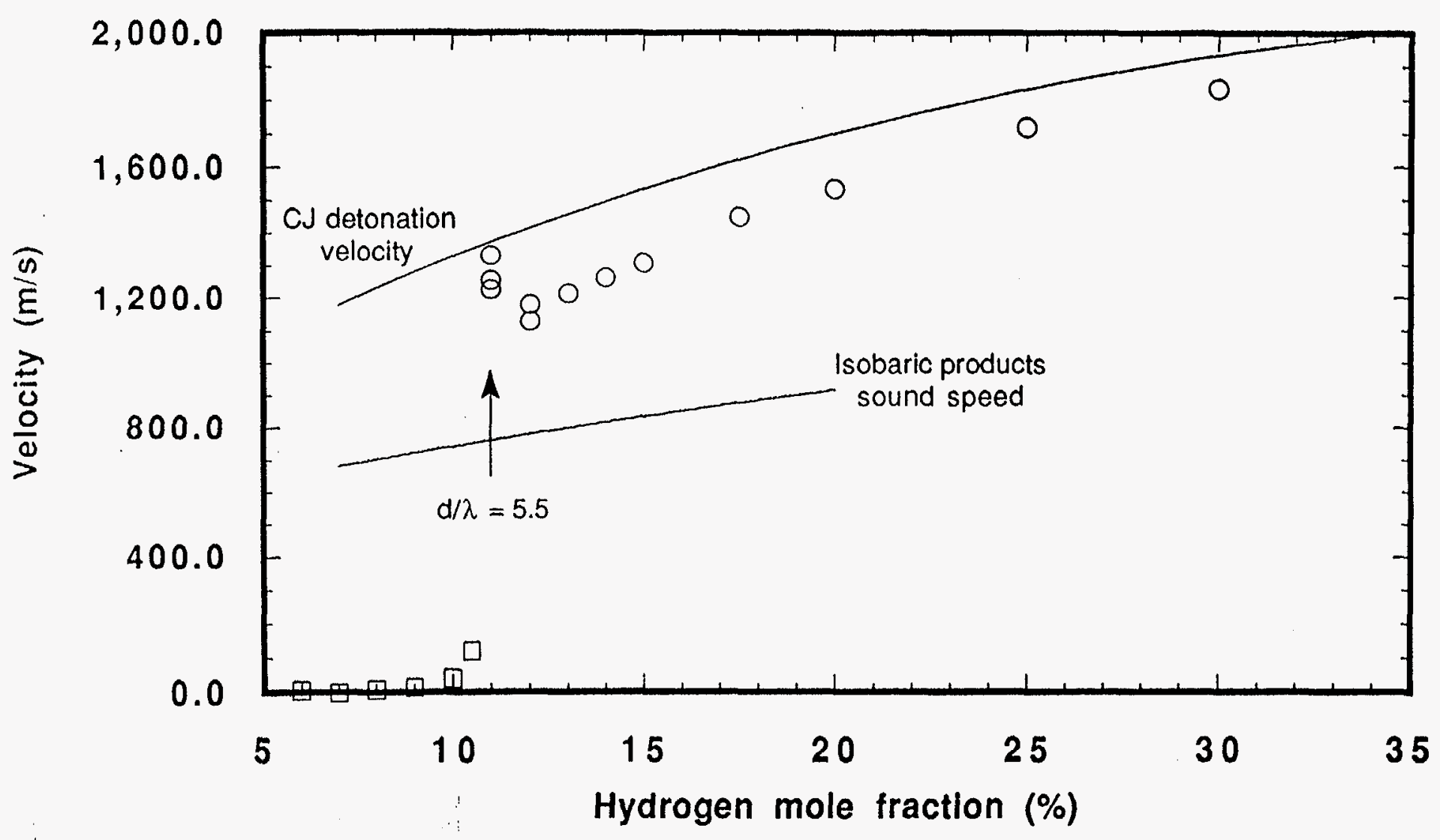

Fig. 5 Combustion front velocity versus hydrogen mole fraction for hydrogen-air mixtures at $650 \mathrm{~K}$ and $0.1 \mathrm{MPa}$. Open circles denote the flame velocity at the end of the vessel. Open squares denote the maximum flame velocity for slow deflagrations. 